\title{
Small-bowel obstruction precipitated by bowel preparation for screening colonoscopy
}

A 55-year-old man with a remote history of appendectomy presented to the emergency department 24 hours after undergoing a screening colonoscopy, complaining of persistent nausea, emesis, and worsening abdominal pain that began during a split-day bowel preparation with low-volume polyethylene glycol and bisacodyl tablets. The patient reported that he developed nausea and generalized abdominal cramping after he finished the first part of bowel preparation and then developed multiple episodes of emesis after the second part. However, his vital signs and abdominal exam were unremarkable and colonoscopy was performed without difficulty. At home he had recurrent nausea, emesis, and worsening abdominal pain, and therefore went to the emergency department. His abdomen was distended, tympanitic, and diffusely tender to palpation, with hypoactive, high-pitched bowel sounds and no peritoneal signs. Plain radiographs of the abdomen revealed no free air, but did indicate distension of the proximal and mid small bowel with multiple air-fluid levels ( $\bullet$ Fig. 1 ).

After conservative management failed, the patient underwent a laparotomy which revealed an obstruction in the ileum secondary to a stricture caused by an adhesion.

The most common cause of small-bowel obstruction (SBO) is adhesions (65\%-75\% of cases) [1]. The literature contains a few case reports of SBO secondary to colonoscopy [2-5]. Ours is the first report of a SBO induced by bowel preparation. Review of the cases of colonoscopy-induced

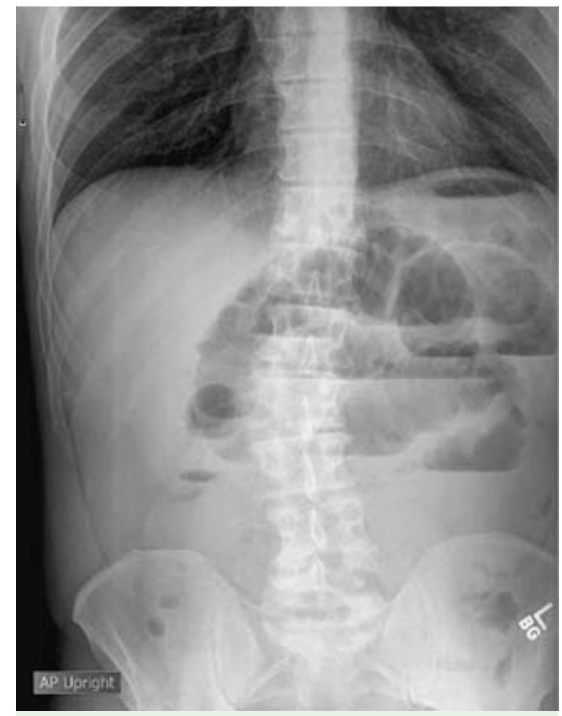

Fig. 1 Plain abdominal radiograph (upright) demonstrating distension of proximal and mid small bowel with multiple air-fluid levels.

SBO, as well as of this present case, found that a common factor was prior abdominal surgery. The fact that symptoms of SBO started almost immediately after the patient's bowel preparation was finished and before his arrival for the colonoscopy makes it less likely that the procedure itself induced SBO. The rare complication of SBO should be considered in a patient presenting with symptoms of nausea, vomiting, and abdominal pain at the time of colonoscopy.

\section{Competing interests: None}

Endoscopy_UCTN_Code_CPL_1AJ_2AB
J. T. Hlivko ${ }^{1}$, E. J. Esber ${ }^{1}$, J. A. Porter ${ }^{2}$, C. H. Kefalas ${ }^{1}$

${ }^{1}$ Department of Medicine, Summa Health System, Akron, Ohio, USA

2 Department of Surgery, Summa Health System, Akron, Ohio, USA

\section{References}

1 Menzies $D$, Ellis $H$. Intestinal obstruction from adhesions - how big is the problem? Ann R Coll Surg Engl 1990; 72: 60-63

2 Zanati SA, Fu A, Kortan P. Routine colonoscopy complicated by small-bowel obstruction. Gastrointest Endosc 2005; 61: 781 - 783

3 Malki SA, Bassett ML, Pavli P. Small bowel obstruction caused by colonoscopy. Gastrointest Endosc 2001; 53: 120 - 121

4 Gonzalez RA, Avila S, Lopez-Roses $L$ et al. Small bowel obstruction and perforation after colonoscopy. Endoscopy 2003; 35: 192

5 Raghavendran K, Novak JM, Amodeo JL et al. Mechanical small bowel obstruction precipitated by colonoscopy. Surg Endosc 2003; 17: 1496

\section{Bibliography}

DOI $10.1055 / \mathrm{s}-0030-1255644$

Endoscopy 2010; 42: E220

(c) Georg Thieme Verlag KG Stuttgart · New York . ISSN 0013-726X

\section{Corresponding author}

\section{J. T. Hlivko, MD}

Department of Medicine Summa Health System

55 Arch Street, Suite 1A

Akron

Ohio 44304

USA

Fax: +1-330-375-3760

jonhlivko@yahoo.com 